\title{
A crítica e a consagração de Helena Kolody no campo literário e intelectual paranaense
}

\section{The critique and the consecration of Helena Kolody in the literary and intellectual field of Paraná}

\author{
Claércio Ivan Schneider ${ }^{*}$ \\ Tiago Boruch ${ }^{* *}$
}

\begin{abstract}
Resumo
O presente artigo objetiva compreender, com o apoio metodológico de Pierre Bourdieu, a crítica e a consagração da poetisa Helena Kolody e de seu projeto criador no campo literário e intelectual paranaense. Buscamos problematizar a posição intelectual da autora bem como analisar, a partir de sua construção poética, as representações regionais que Kolody reproduz em torno da figura do imigrante ideal - religioso, laborioso e modernizador - influenciada pelos ideais do Movimento Paranista. Para isso, percorremos os caminhos da crítica que consolidou o nome da poeta como intérprete "autorizada" do Paraná, bem como buscamos na obra os elementos da identidade, da cultura e do cotidiano eslavo que desempenharam relevante papel na representação dos imigrantes ucranianos. Buscamos demostrar que a consagração da poeta como porta voz da cultura ucraniana no Paraná está intimamente ligada ao temas regionais e ao uso de um conjunto de símbolos, de representações e de memórias que vão ao encontro dos preceitos oficiais que narram a saga dos imigrantes no Paraná. Representação esta que exclui do Paraná a diversidade étnica e social já há muito tempo tematizada por uma historiografia contemporânea.
\end{abstract}

Palavras-chave: Helena Kolody; campo de consagração; Paranismo; imigrantes ucranianos.

Abstract
This article aims to understand, with methodological support by Pierre
Bourdieu, the critique and the consecration of the poetess Helena Kolody
and her creative project in the literary and intellectual paranaense field. We
seek to inquire the author's intellectual position as well as analyze, from its
poetic construction, the regional representations that Kolody reproduces

\footnotetext{
*Doutor em História pela UNESP-Assis. Professor do Curso de História da Unioeste. Professor do PPGH da Unicentro, Campus de Irati-Pr. E-mail: claercios@gmail.com

** Mestre em História pela Unicentro, Campus de Irati. Instrutor na área de Gestão e Comunicação do Serviço Nacional de Aprendizagem Comercial-PR.E-mail: boruch.tiago@gmail.com
} 
around of the ideal immigrant figure - religious, laborious and modernized - influenced by the ideals of the Paranista Movement. For this to happen, we followed the way of criticism that consolidated the name of the poetess as "authorized" interpreter of Paraná, as well as searching in the work the elements of identity, culture and of everyday slavic which played an important role in the representation of Ukrainian immigrants. We seek to demonstrate that the consecration of poetess as spokesperson of Ukrainian culture in the Paraná is connect to regional themes and the use of a set of symbols, representations and memories that meet the official precepts which tell the saga of immigrants in the Paraná. Representation which excludes from the Paraná the ethnic and social diversity described already for a long time by a contemporary historiography.

Keywords: Helena Kolody; consecration field; Paranismo; Ukrainian immigrants.

\section{Introdução}

Sempre que pesquisamos por poetas ou poetizas paranaenses uma lista restrita de nomes aparece como "poetas consagrados". Seja por meio da crítica literária, da imprensa, da nova geração de poetas ou mesmo em diferentes sites da internet, alguns nomes são recorrentes, reconhecidos e consagrados no campo literário paranaense. O poeta Antonio Thadeu Wojciochowski, da nova geração, em entrevista ao Cândido, jornal da Biblioteca Pública do Paraná, afirma que ainda na atualidade a visibilidade que a poesia construída pelos poetas paranaenses alcança, em termos nacionais e mesmo internacionais, é resultado dos caminhos desbravados por poetas precursores locais. Segundo ele: Hoje em dia, muita gente nova faz um bom trabalho. Eles souberam aproveitar o espaço criado por Fernando Amaro, Júlia Costa, Dario Vellozo, Emiliano Perneta, Helena Kolody, Paulo Leminski, Alice Ruiz, Marcos Prado e tantos outros. Antonio afirma que a influência, em especial da poesia de Marcos Prado, de Paulo Leminski e de Helena Kolody, ainda repercute na produção poética atual, sobretudo por terem criado uma identidade: a formação étnica do paranaense fez com que a poesia daqui tenha uma universalidade latente em quase todos os seus autores. ${ }^{1}$

\footnotetext{
${ }^{1}$ WOJCIOCHOWKI, Antonio Thadeu. Entrevista. In: KRIMINICE, Felipe. Especial Poesia: poetas paranaenses. Candido. Disponível em: http://www.candido.bpp.pr.gov.br/modules/conteudo/conteudo. php? conteudo $=24$
} 
Wojciochowski destaca um elemento central para nossa análise que se refere ao papel da identidade étnica do paranaense retratado por meio da criação poética. Esta ênfase na identidade étnica pode ser analisada ao tomarmos como fonte o projeto criador de Helena Kolody, tanto em termos do conteúdo de muitas de suas poesias quanto em termos da visibilidade e do reconhecimento que está representação obtêm por meio da crítica literária.

Neste artigo buscamos identificar e analisar a emergência e a consagração da poetiza Helena Kolody no campo histórico e literário paranaense. Historicizamos a sua trajetória intelectual, apoiando-se em seu projeto criador e em autores que tomam Kolody e seus poemas como objeto de pesquisa. Algumas questões balizam este objetivo: Qual o papel e a relevância de Kolody na história e na literatura paranaense? O que se produziu e se produz de sentidos sobre a poeta e sua obra? Quem e como se consagrou a poeta enquanto intérprete "autorizada" do Paraná? Por quais temáticas históricas se busca identificar a poeta e seu projeto criador?

Como será visto, diferentes autores, dentre eles poetas, literatos e historiadores, produziram e ainda produzem sentidos e significados que consagram a obra de Kolody como intérprete da cultura imigrante no Paraná. Logo, reconhecem e definem o projeto poético da poetiza como portadora de valores paranaenses que se consolidaram, em especial, na perspectiva oficial de valorização dos imigrantes e de sua missão civilizatória no Paraná. Para tanto, aliamos a análise da crítica com a análise de algumas poesias a fim de caracterizar a especificidade de sua construção poética, pautada no registro regional da história dos imigrantes e na imigração ucraniana, tendo como influências o discurso regionalista construído pelo Movimento Paranista. ${ }^{2}$

Este movimento surge ao longo dos anos de 1920 a 1930, criado por intelectuais e artistas preocupados com a construção de uma identidade simbólica progressista e modernista ao Paraná, imaginário republicano permeado pela construção de heróis que dariam um sentido e unidade regional ao Estado. Nesta construção simbólica, o que nos interessa para nossa problematização é identificar as representações construídas em torno dos imigrantes europeus, considerados elementos-chave na ocupação e na dinamização de diferentes

\footnotetext{
${ }^{2}$ Para mais informações buscar os trabalhos de: PEREIRA, Luis Fernando Lopes. Paranismo: cultura e imaginário no Paraná da I República. 1996. Dissertação (Mestrado) - Curso de História, Universidade Federal do Paraná, Curitiba, 1996; REZENDE, Cláudio Joaquim (org.). Paraná espaço e memória: diversos olhares histórico-geográficos. Curitiba, Editora Bagozzi, 2005; BATISTELLA, A. "O paranismo e a invenção da identidade paranaense”. Revista eletrônica de História em reflexão (UFGD), v. 6, 2012; CAMARGO, G. L. V. Paranismo: arte, ideologia e relações sociais no Paraná. 1853-1953. Tese de doutorado em História. Universidade Federal do Paraná, 2013.
} 
regiões no Paraná. Buscamos perceber quais elementos simbólicos paranistas estão presentes ou influenciaram o projeto literário construído por Kolody, como destaque a representação de símbolos da natureza como a araucária, os rios e as florestas da região, e o culto à figura do imigrante ideal do paranismo, sendo europeu, branco, religioso e trabalhador.

Não nos interessa, neste momento, perceber os silêncios ou as exclusões que a poesia de Kolody estabelece para com a presença de outras etnias no Paraná, em especial a indígena e a africana ou mesmo com relação aos outros imigrantes europeus que não sejam os ucranianos, embora isso ajude a entender suas posições intelectuais. Partimos do que Kolody representa, como representa e do reconhecimento e consagração que alcançou e ainda alcança, em especial nos meios oficiais.

Como veremos, Helena Kolody está inserida no campo da história da imigração, em especial por ser filha de imigrantes ucranianos. Nesse sentido, reproduz através dos seus poemas a saga destes em território paranaense, tendo como base tudo que observou, viveu e sentiu, seja por meio de relatos ou experiências. Sua ascendência eslava e a preocupação em representar estes sujeitos por meio da poesia, proporcionaram o reconhecimento de Kolody como a porta-voz dos imigrantes ucranianos. Com poemas simples a poetiza revela o cotidiano, a adaptação e a sensação de pertencimento destes imigrantes para com a formação identitária do paranaense.

É preciso entender a autora, suas poesias e a sua relevância social em sua temporalidade. Para isso, analisamos o seu entorno social e o espaço simbólico de recepção e de produção de sentidos para sua obra. Para alcançar tal objetivo, buscamos em Pierre Bourdieu, em particular o conceito de 'campo literário' utilizado/cunhado por ele, possibilidades mais versáteis de entendimento da engrenagem que envolve a produção, a circulação e o consumo do material artístico literário produzido pela poeta e seus críticos. $\mathrm{O}$ artista pertence ou participa de correntes e escreve para grupos específicos. Segundo Bourdieu:

\begin{abstract}
A representação carismática do escritor como "criador" leva a colocar entre parênteses tudo que se acha inscrito na posição do autor no seio do campo de produção e na trajetória social que para ali o conduziu: de um lado, a gênese e a estrutura do espaço social inteiramente especifico no qual o "criador" esta inserido, e constituído como tal, e onde seu próprio "projeto criador" se formou; do outro lado, a gênese das disposições a uma só vez genéricas e especificas, comuns e singulares, que ele introduziu nessa posição. ${ }^{3}$
\end{abstract}

${ }^{3}$ BOURDIEU, Pierre. As Regras da Arte: Gênese e estrutura do campo literário. São Paulo: Companhia das Letras, 1996, p. 217. 
O que Bourdieu nos diz é que o artista pretende marcar lugar dentro do universo da crítica, investindo em uma compreensão da arte como um fenômeno dinâmico, cuja fruição cresce na razão direta do entendimento da fluidez das "posições" e "tomadas de posição" dentro de um sistema discursivo que alimenta a contradição de buscar encantar o presente e aspirar ao eterno.

Também os intelectuais por detrás das instituições oficiais, responsáveis pela construção da história oficial, podem ser entendidos como porta vozes sensíveis e emotivos que contribuem para a representação de uma visão da história harmônica dos imigrantes considerados por estes os elementos chave do progresso no Paraná. Pensando nosso objeto ponderamos: quais razões e sentimentos qualificam a realidade nos poemas de Kolody? Como a imigração ucraniana e outros temas na sua obra constroem um conjunto de significados para uma identidade, ou cultura? Nesse caso, é preciso perceber a trajetória social e cultural em que as representações do mundo social resultam do encontro de aspectos que a autora recria no imaginário de situações individuais e coletivas, ou seja, considerar os fatos e as experiências de vida levados como inspiração e base em sua escrita poética.

A representação que Kolody constrói em torno dos imigrantes eslavos no Paraná é reconhecida e legitimada, como veremos, na medida em que revela e defende o habitus do grupo que poetiza. Os códigos culturais, as práticas, os sentimentos e as expectativa são compartilhadas por todos que defendem estes sujeitos históricos no Paraná. Logo, a narrativa poética de Kolody representa este imaginário oficial focado no imigrante ideal.

Para Bourdieu o conceito de habitus surge da necessidade de apreender as relações de afinidade entre o comportamento dos agentes e as estruturas e condicionamentos sociais. Ou seja, os imigrantes representados na poética kolodyana, estão ligados a agentes estruturais e relações sociais do meio em que vivem e se relacionam. Habitus, para Pierre Bourdieu, surge então como um conceito capaz de conciliar a oposição aparente entre realidade exterior e as realidades individuais. Segundo Bourdieu, o habitus são: [...] sistema de disposições socialmente constituídas que, enquanto estruturas estruturadas e estruturantes, constituem o princípio gerador e unificador do conjunto das práticas e das ideologias características de um grupo de agentes. ${ }^{4}$

O habitus inclui tanto as representações sobre si e sobre a realidade, como também o sistema de práticas em que a pessoa se inclui, os valores e crenças que veicula, suas aspirações, identificações. Helena Kolody poetiza o

${ }^{4}$ BOURDIEU, Pierre. A economia das trocas simbólicas. São Paulo: Perspectiva. 2007, p. 191. Disponível em: https://cbd0282.files.wordpress.com/2013/02/bourdieu-pierre-a-economia-das-trocas-simbc3b3licas.pdf 
habitus dos eslavos sobrevalorizando-os como elementos chaves de identificação do grupo. O papel do intelectual como intérprete do habitus nos processos sociais é fundamental, isso porque, referenciando-se em Pierre Bourdieu, o intelectual é aquele que detêm o discurso sobre o mundo social, ou melhor:

Aquele que detêm um poder específico, o poder propriamente simbólico de fazer com que se veja e se acredite, de trazer à luz, ao estado explícito, objetivado, experiências mais ou menos confusas, fluídas, não formuladas, e até não formuláveis, do mundo natural e do mundo social, e, por essa via, fazê-las existir. ${ }^{5}$

Bourdieu nos ajuda a problematizar o poder simbólico do projeto artístico de Kolody. A autora é reconhecida, tem relevância social e busca a construção do imaginário ucraniano. Kolody referência a imigração eslava ao longo de toda a sua obra, atribuindo sentidos aos imigrantes de acordo com a época que escreve seus poemas, fazendo-os existir, de modo que sua produção poética interaja com a história em seus aspectos, suas formas de desenvolvimento, de adaptação e de preservação cultural.

\section{Helena Kolody: os caminhos da consagração como poeta paranaense}

Ao longo de sua trajetória intelectual Helena Kolody (1912-2004) acumulou inúmeros prêmios literários e também recebeu diversas homenagens. Constatação que mostra a sua relevância no campo literário, sendo admirada por outros autores de destaque no cenário poético brasileiro, como Paulo Leminski, Cecília Meireles e Carlos Drummond de Andrade. Entre os prêmios e homenagens que recebeu citamos: Diploma de Mérito Literário da Prefeitura de Curitiba (1985); título de Cidadã Honorária de Curitiba (1987); A criação do "Concurso Nacional de Poesia Helena Kolody", realizado anualmente pela Secretaria da Cultura do Paraná em sua homenagem (1988); Gravação e publicação de seu depoimento para o Museu da Imagem e do Som do Paraná (1989); Eleita para a Academia Paranaense de Letras $^{6}$ (1991); Produção do filme A Babel

\footnotetext{
${ }^{5}$ BOURDIEU, Pierre. Os Usos sociais da ciência. Por uma sociologia clínica do campo científico. São Paulo: Editora da UNESP, 2004, p. 176.

${ }^{6}$ A Academia Paranaense de Letras foi fundada em Curitiba, em 26 de setembro de 1936, sucedendo a antiga Academia de Letras do Paraná, criada em 1922 e dissolvida por motivos políticos. A recriação de uma entidade cultural representativa da cultura do Estado, deu-se por estímulo e influência da Academia Carioca de Letras e da Federação das Academias de Letras do Brasil. Exerceu a liderança, nesse propósito, o Professor Dr. Ulysses Vieira que reagrupou intelectuais dispostos a resgatar os valores acadêmicos dispersos por força das velhas dissidências. Da extinta Academia de Letras, alinharam-se na promoção da nova instituição nascente, figuras de relevo, tais como Dom Alberto José Gonçalves, João Cândido, Sebastião Paraná, Dario Velozzo, Santa Rita, Leônidas Loyola, Pamphilo d'Assupção, Silveira Neto, Tasso da Silveira, Andrade Muricy, Leôncio Correia, Lacerda Pinto, Azevedo Macedo e Romario Martins. (http://www.academiapr.org.br).
} 
de Luz, do cineasta Sylvio Back, no qual se homenageia os 80 anos da poetisa, tendo recebido o prêmio de melhor curta-metragem e melhor montagem no $25^{\circ}$ Festival de Brasília (1992); Exposição em homenagem aos 90 anos da poetisa, na Biblioteca Pública do Paraná (2002); Recebe o título de "Doutora Honoris Causa" pela Universidade Federal do Paraná (2003). Sobre seu reconhecimento e a entrada na Academia Paranaense de Letras, a poetiza afirmou: Fui eleita para a Academia Paranaense de Letras aos 80 anos de idade e a segunda mulher a ser admitida no fechado círculo masculino. A primeira, Pompilia Lopez dos Santos, foi quem me abriu as portas. ${ }^{7}$

O reconhecimento de Kolody veio na maturidade de sua carreira e, ainda hoje, seu nome, como personalidade da literatura do Estado, é homenageado quando atribuído a nomes de escolas e concursos poéticos. Nas palavras da autora:

Meu nome não é mais um desenho a giz: ele batiza as Bibliotecas dos Colégios Presidente Kenedy, Nivaldo Braga e Gelvira Correa Pacheco (Curitiba); as Escolas de Ensino de Primeiro Grau de Cambé e o Colégio Estadual de Terra Boa; duas salas de aulas: uma no Instituto de Educação do Paraná e a outra na Escola Meu Cantinho - Precisão. Sou até nome de sanduíche no Bar Poesia... ${ }^{8}$

Helena Kolody inicia sua trajetória literária publicando sua primeira poesia, intitulada "Lágrima", no ano de 1928, em uma revista chamada 0 Garoto, editada por jovens na capital paranaense, Curitiba. Porém, nessa época a autora dedica maior tempo ao magistério, e apenas no ano de 1941 é que publica seu primeiro livro, Paisagem Interior, publicado às próprias custas de Helena. Nesta mesma época a autora encontra grupos em que se insere em busca de um maior aperfeiçoamento artístico. Segundo Luiza Cristina dos Santos Fontes:

Na década de 30, foi fundada a Academia de Letras José de Alencar. Aníbal Calderari, diretor do Colégio Partenon, cedeu o salão nobre do estabelecimento para as reuniões semanais da Academia. Todos os domingos, pela manhã, reuniam-se jovens e velhos (os moços em maior número), para falar de literatura. Cada um lia o que o outro tinha escrito, ouvia a leitura do trabalho dos outros e discutia o que havia sido feito. Helena saia da reunião vibrando, motivada pelo convívio com os outros do mesmo métier. "A lágrima” foi seu primeiro poema publicado, em 1928, na revista O Garoto, editada por um grupo de estudantes. ${ }^{9}$

\footnotetext{
${ }^{7}$ KOLODY, Helena. Sinfonia da vida. Curitiba: Editora Letraviva, 1997, p. 91.

${ }^{8}$ Ibidem, p. 13.

${ }^{9}$ FONTES, Luísa Cristina dos Santos. Carbono e diamante: uma biografia ilustrada. Tese de doutorado. UFSC, Florianópolis, SC, 2012, p. 170.
} 
Ao longo da carreira e atravessando inúmeras fases, Kolody manteve-se publicando seus livros, sem reconhecimento ou procura de editoras. Foram 13 obras publicadas pelo seu próprio investimento, mesmo seu nome sendo reconhecido na capital paranaense e admirada por poetas importantes da literatura nacional. Foi só após a tradução de seus poemas para a língua de seus antepassados ucranianos que Kolody consegue realizar o sonho de ter seu primeiro livro publicado por uma editora. Vejamos nas palavras de Kolody ao responder a pergunta de José Wille, sobre o seu reconhecimento nacional:

Começou em 1988, quando foi publicado pela editora Criar, de Roberto Gomes, o livro "Viagem no Espelho", que é minha obra mais completa. Porque o que surgiu depois, por exemplo, foi um livro ucraniano, foram traduções em outras línguas das próprias poesias daqui, ou reuniões ou interpretações. Também houve "Sinfonia da Vida", organizado pela Tereza de Rezende, mas são comentários de poesias que existem aqui. ${ }^{10}$

E foi através da obra Viagem no Espelho que segundo a própria autora obteve sua consagração como poeta e escritora:

A partir da "Viagem no Espelho", porque, antes disso, o meu era um nome local. Alguns me conheciam mais longe, porque eu mandava minhas poesias para o estrangeiro, mas era pouca gente. A partir daí, foi um conhecimento maior. Foi um total de vinte publicações. ${ }^{11}$

Mesmo se inserindo no campo literário muito jovem, e com inúmeros trabalhos e críticas de autores sobre a poetisa, seu reconhecimento se restringe ao Estado do Paraná, mais especificamente em Curitiba. Como podemos ver na citação de Luiza Cristina dos Santos Fontes, em sua tese de doutorado em literatura, a qual teve Helena Kolody como tema central de pesquisa:

Reverberam nos mais de 500 textos, localizados e elencados em sua fortuna
crítica, o aval de Adonias Filho, Alice Ruiz, Andrade Muricy, Arnaldo Antunes,
Carlos Drummond de Andrade, Cecília Meireles, Euclides Bandeira, Fanny Luiza
Dupré, Ítalo Moriconi, Josely Vianna Baptista, Miguel Sanches Neto, Nelly
Novaes Coelho, Olga Savary, Paulo Leminski, Paulo Venturelli, Reinoldo Atem,
Roberto Gomes, Rodrigo Júnior, Sérgio Rubens Sossélla, Sylvio Back, Tasso da
Silveira, Temístocles Linhares, Valfrido Piloto, Valêncio Xavier, Wilson Bueno,
Wilson Martins, entre muitos outros, ao longo do século XX e transbordando-o.
Todos seus contemporâneos, de Euclides Bandeira, nascido em 1877, a Miguel
Sanches Neto, nascido em 1965. Beira a milagre! Independentemente de gênero,
circulou, aliás, circula, com desenvoltura, entre todas as turmas literárias: os

${ }^{10}$ WILLE, José. A eterna solidão de Helena Kolody. Entrevista. Portal Memória Brasileira. Disponível em: http://www.jws.com.br/2016/02/a-eterna-solidao-de-helena-kolody/

${ }^{11}$ Ibidem. 
românticos, os simbolistas, os haicaístas, os parnasianos, os modernistas, os espiritualistas, os vanguardistas... É quase uma unanimidade... No entanto, surpreendentemente, não obstante a riqueza de sua fortuna crítica, sua obra, ainda hoje, é pouquíssimo conhecida além das fronteiras de seu estado natal. ${ }^{12}$

Acredita-se que Kolody não conseguiu atingir o reconhecimento nacional com sua poesia principalmente devido ao fato de seu projeto criador focar e evidenciar com maior relevo a temática da cultura eslava dos imigrantes ucranianos no Paraná. Diferente de outros autores que foram reconhecidos nacionalmente por abordarem culturas imigrantes, levando-as a patamares de alto reconhecimento na literatura brasileira, como os alemães no Rio Grande do Sul por Érico Verissimo e os italianos em São Paulo por António de Alcântara Machado. Vejamos a citação abaixo do crítico literário Wilson Martins:

Bastante reverenciada em sua terra não apenas pela naturalidade regional, mas também acrescentando a voz do imigrante à temática da poesia brasileira (o que já havia sido feito por outros, mas de perspectivas nacionais). [...] ela vive o paradoxo de ser, como poeta, figura exponencial das letras paranaenses (ou, mais precisamente, curitibanas), sem ter conseguido gravar o seu nome e a sua obra no quadro mais amplo das letras brasileira. ${ }^{13}$

Nota-se que o autor situa o reconhecimento do valor da obra de Kolody restrito ao Estado, referindo-se a Curitiba, cidade em que Helena viveu a maior parte de sua vida, limitando sua obra a poucos paranaenses, e poucos descendentes eslavos, visto que as maiores concentrações estão no interior do Estado. Wilson Martins fala ainda que Helena Kolody é poeta do Paraná não apenas pela naturalidade regional, mas também por haver acrescentado a voz do imigrante à temática da poesia brasileira (o que já havia sido feito por outros, mas de perspectivas nacionais). A consagração de Helena Kolody se dá por críticos como Martins e posteriormente, pela Academia Paranaense de Letras. Ou ainda, como coloca o historiador Paulo Augusto Tamanini:

\begin{abstract}
A lembrança do que seus pais disseram sobre a travessia do Atlântico a inspirou em escrever sobre uma Ucrânia que não conheceu, mas que a imaginou e a eternizou sobre as linhas de folhas de papel. Imagens e sons apreendidos quando criança fizeram da menina sonhadora a grande senhora dos versos da nação ucraniana, digna do reconhecimento por parte da academia que lhe outorgou um lugar de distinção. ${ }^{14}$
\end{abstract}

\footnotetext{
${ }^{12}$ FONTES, op. cit., p. 35.

${ }^{13}$ MARTINS, W. Poetas do Paraná. Jornal do Brasil. Rio de Janeiro, 19 março de 1994.

${ }^{14}$ TAMANINI, Paulo Augusto. A ucraneidade em poesia: história e literatura na arte de escrever. Revista Intratextos. v. 3, p. 33-43, 2011, p. 37.
} 
Vemos o seu reconhecimento no Paraná também por meio de autores consagrados, como Paulo Leminski, que no ano de 1968, ao fazer um prefácio para um livro do poeta Mário Stasiak, escreveu: "Lembrai-vos, irmãos, que o maior gênio poético do Paraná é de raiz eslava, sendo Helena Kolody (pronunciar: Guélena Kolódi). ${ }^{15}$ Vale ressaltar que Paulo Leminski, também era de ascendência eslava, filho de poloneses imigrados para o Brasil. Em entrevista para a Gazeta do Povo de 1985, Paulo Leminski intitula Kolody como padroeira dos escritores paranaenses, destacando a essência em sua poesia, principalmente nos Haikais, no qual Helena foi pioneira no Brasil. Seguem as palavras de Leminski:

Mas tudo isso que eu digo não passaria de uma efusão sentimentalóide, se a poesia de Helena não se sustentasse em nível de linguagem, de design, de essência. Quer dizer, porém, de um poeta que chega, de repente, e apenas, te diz num poema de duas linhas, "para quem viaja ao encontro do sol é sempre madrugada". "Essências e medulas", assim definia Pound a poesia. E esse era o nome que eu daria para um ensaio sobre a poesia da nossa padroeira. ${ }^{16}$

Já Carlos Drummond de Andrade enviou, em 1980, uma pequena carta à poeta, onde dizia: Tão simples, tão pura - e tão funda - a poesia de Infinito Presente. Você domina a arte de exprimir o máximo no mínimo, e com que meditativa sensibilidade! $!^{17}$

Helena, segundo a crítica literária, era a junção de várias correntes literárias, desde o Movimento Simbolista às influências do Movimento Paranista, mas sua obra se reflete como moderna por sua composição, sua noção de ritmo, o verso livre e sua ênfase na linguagem simbólica. Esse era o estilo e a marca da sua escrita, moderna com influencias do Movimento Simbolista. Segundo Antonio Donizeti da Cruz, um dos estudiosos de Helena Kolody, a poeta imprime o moderno em sua obra, em uma conspiração simbólica:

Na base da criação kolodyana estão o senso de trabalho poético e a noção de ritmo, entre outros procedimentos. Optar pelo verso livre, no final da década de 30 e início da de 40, quando começa a escrever e publicar, quando boa parte da poesia escrita no Paraná se resumia à arte poética metrificada e do soneto, significou para a poeta questionar a rigidez da métrica parnasiana e, ao mesmo tempo, levar adiante as pesquisas da musicalidade e do simbolismo brasileiro. Nesse sentido, nota-se em seus primeiros livros uma maior ênfase na linguagem simbólica. Grandes nomes da poesia modernista brasileira como

\footnotetext{
${ }^{15}$ LEMINSKI, Paulo. Prefácio. In: STASIAK, Mário. Auto de Fé Ocidental. Curitiba, Escala, 1968.

${ }^{16}$ LEMINSKI, Paulo. Santa Helena Kolody. Gazeta do Povo. Curitiba, 26 jun. 1985, p. 11.

${ }^{17}$ ANDRADE, Carlos Drummond de. Informação presente no site https://cdeassis.wordpress.com/ Acessado em 22/05/2018.
} 
Manuel Bandeira, Cecília Meireles, Ronald de Carvalho, Mario Quintana, entre outros, iniciaram suas incursões poéticas compondo versos com influências simbolistas. Kolody também vivenciou estas experiências. Dessa forma, assumir o verso livre foi para ela uma maneira de refletir sobre o que pode haver de trabalho efetivamente poético, ou seja, que vai além das simples resposta a imposição e regras dos versos metrificados. ${ }^{18}$

Assumindo os versos livres, Helena Kolody mostra, desde sua primeira publicação Paisagem Interior de 1943, traços modernos, por sua temática diversificada, não seguindo um tema especifico em cada obra. Ainda com Cruz:

As primeiras obras de Helena Kolody, tais como Paisagem interior, Música submersa e A sombra no rio, inserem-se na estética modernista com uma temática acentuada pelo registro do cotidiano, as angústias frente à passagem temporal, a valorização do passado, a busca do subconsciente e do inconsciente. A poeta, por conhecer Tasso da Silveira, tem contato com a produção literária do grupo Festa, liderado pelo referido escritor e poeta. O grupo visava, segundo Bella Josef, "redefinir em termos de reespiritualização, o Modernismo". ${ }^{19}$

Cruz nos ajuda a identificar os espaços e grupos que influenciaram e ascendem o projeto artístico de Kolody "a visibilidade" e ao reconhecimento regional. Mostra que a artista estava consciente do campo literário e vai buscar o contato, no caso, com o grupo Festa. ${ }^{20}$

Helena Kolody também teve seu reconhecimento por meio do haicai, ${ }^{21}$ uma forma poética de origem japonesa, cuja característica é a concisão, ou seja, a arte de dizer o máximo com o mínimo. Foi a primeira mulher a publicar haicais no Brasil, em 1941. Essa forma poética oriental a acompanhou durante sua carreira. Rendendo prêmios e sendo expoente do gênero no Estado. Vejamos na fala do haicaísta e editor Jose Marins:

Recebeu da Comunidade Nipo-Brasileira de Curitiba a Outorga de nome haicaísta Reika. Foi homenageada pela Feira do Poeta de Curitiba e recebeu o título de Cidadã Honorária de Curitiba e de Doutora Honoris Causa, pela Universidade Federal do Paraná. Tornou-se patronesse das cadeiras do Centro

\footnotetext{
${ }^{18} \mathrm{CRUZ}$, Antonio Donizeti da. A construção poética em Helena Kolody. 2006. Ciênc. Let., Porto Alegre, n.39, p. 264-278, jan./jun, p. 267.

${ }^{19}$ Ibidem, p. 267.

${ }^{20} \mathrm{O}$ Grupo festa foi um grupo de poetas modernistas da década de 1920 e 30 que tinha uma proposta de um retorno às raízes simbolistas e cultivava uma linha espiritualista e a tradição católica, os principais nomes foram: Cecília Meireles, Murilo Araujo, José Cândido de Andrade Muricy, Adonias Filho e Tasso da Silveira. Para mais informações consultar: MIRANDA, Luciana L. de. Intelectuais e modernismo brasileiro: nos rastros do Grupo Festa, anos de 1920. Anais do XXIX Encontro de História Nacional. Disponível em: http:// www.snh2017.anpuh.org/resources/anais/54/1488811096_ARQUIVO_Textoprovisorio.pdf

${ }^{21}$ Para maiores informações sobre os Haikais de Helena Kolody, consultar: http://www.kakinet.com/ caqui/kolody.php?t=8
} 
Paranaense Feminino de Cultura e foi eleita para a Academia Paranaense de Letras. $^{22}$

Como exemplo atentamos ao Haikai Ipês floridos, árvore considerada pelos paranistas típica da paisagem do Estado:

\author{
Festa das lanternas! \\ Os ipês se iluminaram \\ de globos cor-de-ouro. ${ }^{23}$
}

Como está sendo visto, a sua representatividade e consagração é construída e consolidada por pesquisadores e críticos que tomam a autora e seu projeto criador como alvo de estudo e referência. Luiza Cristina dos Santos Fontes, por exemplo, compara sua poética como um símbolo cultural paranaense, assim como o pinheiro, a arquitetura das casas ou a forma de falar:

[...] a poética de Helena Kolody delimita um espaço de tonalidades muito nossas. As janelas, a terra e o tempo de Helena descortinam-se para o campo do onirismo. Na geometria do sonho, em suas linhas, reencontraremos a intimidade do passado. Helena Kolody é um dos nomes mais referenciais do Paraná. Paranista como o pinheiro em nossa flora, como os lambrequins em nossa arquitetura, como o "leite quente" em nosso falar. ${ }^{24}$

Fontes dá os contornos da consagração em torno de Kolody. As referências paranistas são aplicadas à personalidade de Helena engrandecida como a araucária. É dessa forma também que a poetisa representa o Paraná, território que acolherá os imigrantes. A arquitetura das casas, o modo e expressões ao falar como "leite quente", são marcas da poesia kolodyana. Ao referir-se a esses elementos, a autora coloca a regionalidade paranista em sua obra, e por isso a sua consagração frente a crítica literária no Paraná. Kolody não incorpora em seus poemas representações fora desse contexto dos imigrantes. Em seus poemas a visão em torno do Estado paranaense é construída pelo trabalho dos imigrantes, destacando os ucranianos, não se atentando para outras etnias e povos presentes no mesmo território. Vejamos, como exemplo, o poema intitulado "Araucária", que ajuda a demonstrar a influência de símbolos construídos pelo paranistas:

\footnotetext{
${ }^{22}$ MARINS, José. Haicai. Palestra na Biblioteca Pública do Paraná. Curitiba, 2004. Disponível em: https://www. algosobre.com.br/haikai/o-haikai-no-parana.html

${ }^{23}$ KOLODY, Helena. Viagem no espelho. Curitiba: Editora da UFPR. 5a . Ed., 2001, p. 23.

${ }^{24}$ FONTES, op. cit., p. 171.
} 


\author{
Nasci forte e altiva, \\ Solitária. \\ Ascendo em linha reta \\ Uma coluna verde-escura \\ No verde cambiante da campina. \\ Estendo braços hirtos e serenos \\ Não há na minha fronte \\ Nem veludos quentes de folhas \\ Nem risos vermelhos de flores, \\ Nem vinhos estoantes de perfumes. \\ Só há o odor agreste da resina \\ E o sabor primitivo dos frutos. \\ Espalmo a taça verde no infinito. \\ Embalo o sono dos ninhos \\ Ocultos em meus espinhos, \\ Na silente nudez do meu isolamento. ${ }^{25}$
}

Assim como a araucária, símbolo imponente construído para o Paraná, Helena foi considerada símbolo da poesia do Estado, justamente por considerar e exaltar os símbolos criados pelo Movimento Paranista. Percebemos essa influência ao vermos que a araucária já havia sido cultuada por poetas paranistas antecessores de Helena. Vejamos um trecho do poema de Pamphilo d'Assumpção citado por Luis Fernando Lopez Pereira em seu trabalho Paranismo: cultura e imaginário no Paraná da primeira república: Pinheiro é a mais altiva, a mais inflexível e erecta das nossas arvore. A palmeira real, elegante, esguia, eleva-se também para o céo em busca de luz e do azulmas é débil e flexuosa. ${ }^{26}$ Isso se deve, segundo Pereira, as inúmeras lendas publicadas em revistas da época exaltando o pinheiro como símbolo do Estado, considerado o símbolo maior do movimento. Nas palavras de Pereira: Aliás, as principais lendas reproduzidas na revista versam sobre o pinheiro (que se configurará no símbolo máximo paranista) ou sobre os mitos de origem da cidade de Curitiba. ${ }^{27}$

Essa imagem do imigrante ideal ganhou destaque no paranismo, assim como os símbolos. A intenção dos paranistas não era a aculturação dos imigrantes, mas sim que a heterogeneidade presente no território pudesse ser

\footnotetext{
${ }^{25}$ KOLODY, Helena. Araucária. In: Paisagem Interior. 1941.

${ }^{26}$ PEREIRA, Luis Fernando Lopes. Paranismo: cultura e imaginário no paraná da I República. 1996. Dissertação em História, Universidade Federal do Paraná, Curitiba, 1996, p. 148.

${ }^{27}$ Ibidem, p. 146.
} 
pensada a partir de um Estado homogêneo construído por meio da imigração de diferentes grupos europeus, constituindo uma particularidade regional em relação ao resto do país. A intenção era forjar uma identidade europeizada valorizavam-se os imigrantes que estivessem dispostos a contribuir com o crescimento do Estado, principalmente por meio do trabalho morigerado, da religião e do sentido civilizador. Segundo Pereira:

A intenção paranista era, portanto, forjar um novo Paraná, um estado com
identidade e com características particulares que diferenciasse o povo da
terra deste estado do restante do país. Identidade impregnada pelas idéias
de ordem e progresso, trabalho e justiça, criado por uma gente trabalhadora,
pouco importando sua procedência com tanto que demonstrassem tal afeição
realizando algo de concreto nas terras paranaenses; desta forma estariam
colaborando não somente com a construção de um Paraná melhor, mas
também na criação de uma Nação e até mesmo na difusão de um sentimento
de humanidade. ${ }^{28}$

A visão do imigrante trabalhador, religioso, apegado à terra e disposto a fincar raízes no Estado perpassa nas poesias de Kolody. Um imaginário recriado por meio do relato de ações, de experiências e de memórias, uma releitura, portanto, dos sentidos construídos pelos intelectuais do Movimento Paranista. Tudo isso implica na ampla manifestação do imaginário na linguagem presente nos poemas. Segundo Sandra Jatahy Pesavento:

O imaginário existe em função do real que o produz e do social que o legitima, existe para confirmar, negar, transfigurar ou ultrapassar a realidade. 0 imaginário compõe-se de representações sobre o mundo do vivido, do visível e do experimentado, mas também sobre os sonhos, desejos e medos de cada época, sobre o não tangível nem visível, mas que passa a existir e ter força de real para aqueles que o vivenciam..$^{29}$

Com Pesavento, percebemos que as representações do mundo vivido partem do imaginário de quem protagoniza determinada história. Ao refletir as experiências de Helena Kolody, a qual retrata em sua obra o seu mundo vivido, percebemos a representação do imaginário em função do real, ao conciliar seu universo social em seus poemas, legitimando, como propõe Pesavento, as experiências para aqueles que a vivenciaram. Assim, interpretar e analisar as poesias de Kolody partindo das representações e de sua posição

\footnotetext{
${ }^{28}$ Ibidem, p. 88.

${ }^{29}$ PESAVENTO, Sandra Jatahy. Cultura e Representações, uma trajetória. Anos 90. Porto Alegre, v. 13, n. 23/24, p.45-58, jan./dez. 2006, p. 50. Disponível em: http://www.seer.ufrgs.br/anos90/article/viewFile/6395/3837
} 
intelectual, determina um caminho entre a história sensível e o imaginário. Seguimos com Pesavento:

[...] sensibilidades remetem ao mundo do imaginário, da cultura e de seu conjunto de significações construído sobre o mundo. Mesmo que tais representações sensíveis se refiram a algo que não tenha existência real comprovada, o que se coloca na pauta de análise é a realidade do sentimento, a experiência sensível de viver e enfrentar aquela representação. ${ }^{30}$

Neste exercício poético de representar, de fazer existir, Kolody tematiza aspectos sensíveis que contemplam a forma de vida dos imigrantes, seu habitus. Parte de uma história de afirmação do povo eslavo nas regiões do Estado onde foram inseridos, evidencia o lado de luta e de glória dos imigrantes, as conquistas diárias, sua cultura, pouco atentando para as derrotas ou situações contrarias a afirmação dos mesmos. Como no poema "Imigrantes Eslavos", da obra A Sombra do Rio, de 1954.

\author{
Cabeça branca do neto \\ Cabeça branca do avô. \\ Luar noturno e geada, \\ Que é orvalho da madrugada. \\ Vão conversando...E se entendem \\ Numa linguagem difusa: \\ O mesmo vago sorriso, \\ A mesma fala confusa. ${ }^{31}$
}

Neste poema percebemos a língua ucraniana, marca da cultura eslava presente nas regiões ocupadas no Paraná e a continuidade linguística, passando para a geração que nascia no Brasil. Algumas características dos imigrantes remetem ao discurso de exaltação da cultura ucraniana em relação ao estereótipo de imigrante buscado nas levas imigratórias e valorizados pelo Movimento Paranista. Seriam eles europeus, de pele branca e de religião católica. Os poemas kolodyanos sobre a religião incorporam não só a visão do imigrante perfeito para o estado mas a continuação da cultura e identidade ucraniana. Vejamos o poema "Prece", da obra Paisagem Inteiror, de 1941, onde nota-se a expressão de fé da poetisa em um poema que mais parece uma oração:

\footnotetext{
${ }^{30}$ PESAVENTO, Sandra Jatahy. Sensibilidades: escrita e leitura da alma. In: LANGUE, Frédérique (org.). Sensibilidades na história: memórias singulares e identidades sociais. Porto Alegre: Editora da UFRGS, 2007, p. 20. ${ }^{31}$ KOLODY, Helena. Imigrantes eslavos. In: Viagem no espelho. Curitiba: Editora da UFPR. 5ª. Ed., 2001, p. 176.
} 
Concede-me, Senhor, a graça de ser boa

De ser o coração singelo que perdoa,

A solicita mão que espalha, sem medidas,

Estrelas pela noite escura de outras vidas

E tira d alma alheia o espinho que magoa. ${ }^{32}$

Para Pierre Bourdieu, o artista está sujeito as tensões do seu campo, e sua escrita está ligado a sua vida. Percebemos que Helena Kolody, ao utilizar suas experiências de vida, suas memórias e histórias vividas em seus poemas, se coloca como parte da arte, está inserida de forma direta ao que escreve. No campo da História, Paulo Augusto Tamanini analisa a religiosidade e a ligação com a cultura ucraniana como elementos centrais em sua obra:

Seus versos não são observados apenas pelo viés da arte literária, mas como instrumento indiciário do acontecido que pode, além de explicar as expressões e os contornos subjetivos de sua obra, procurar compreender com mais largueza os sentidos e os significados que os fatos desencadearam em sua gente. Os versos da autora auto decifram sua latente ucraneidade. ${ }^{33}$

Tamanini ressalta a ucraniedade expressa nos poemas de Kolody, e que proporciona estudos nos mais diversos campos do conhecimento. Tamanini afirma que pela autora a Ucrânia ganhou destaque antes mesmo de ser reconhecida como uma nação: A Ucrânia da poesia e do sonho ganhou território e lugar de legitimação na Literatura paranaense, antes mesmo de ser reconhecida como Nação em 1991, quando se desvencilhou de uma União Soviética já quebrantada. ${ }^{34}$

Vejamos essa analise tendo como aporte as palavras de Bourdieu:

A análise cientifica, quando é capaz de trazer a luz o que torna a obra de arte necessária, ou seja, a formula formadora, o principio gerador, a razão de ser, fornece a experiência artística, e ao prazer que a acompanha, sua melhor justificação, seu mais rico alimento. Através dela, o amor sensível pela obra pode realizar-se em uma espécie de amor intellectualis rei, assimilação do objeto ao sujeito e imersão do sujeito no objeto, submissão ativa a necessidade singular do objeto literário. ${ }^{35}$

A experiência artística de Kolody está ligada ao modo que ela utiliza seus objetos nos poemas, seja o imigrante, os símbolos do Paraná, a religiosidade, o cotidiano e a natureza. Percebemos isso na imersão da autora, seja no

\footnotetext{
${ }^{32}$ Ibidem, p. 217.

${ }^{33}$ TAMANINI, op. cit., p. 36.

${ }^{34}$ Ibidem, p. 37.

${ }^{35}$ BOURDIEU, Pierre. 0 poder simbólico. Rio de Janeiro: Bertrand Brasil, 2010, p. 15.
} 
mundo rural ou no espaço urbano, onde retrata a vida dos imigrantes. Segundo Bourdieu, a vida do escritor está a sombra de sua escrita, contudo a escrita é sua forma de vida. Desta maneira, percebemos o porquê da autora escrever sobre o povo eslavo imigrante no Paraná. Ela faz parte de tal contingente, sente-se como parte da história, logo sua arte poética é reflexo das suas aspirações e tensões no campo literário, como também na sua experiência de vida. Os sentimentos e as sensibilidades impressos nos poemas representam Helena como porta voz dos imigrantes ucranianos no Paraná, ${ }^{36}$ através de sua poesia. A presença de Kolody como objeto de seus poemas é retratado por Fontes:

Considerando que a literatura é o campo propicio para se observar, entre outras coisas, a construção de subjetividades a partir da tensão que se estabelece entre lugares sociais e familiares, histórias individuais e modos narrativos, a identidade da mulher que emerge em todos estes textos (como objeto que se apresenta e como sujeito que se escreve) - os seus ou sobre os seus -, constitui-se pela interseção tensão entre estes elementos. "Afinal, eu vivi, ou sonhei que vivi?" ${ }^{37}$

Vemos, então, que a sua proximidade e familiaridade com os imigrantes ucranianos permitiam que seus versos encontrassem ressonâncias significativas nos elementos que fazem parte de sua poética. Kolody, constrói representações e denota a saga dos imigrantes revelando subjetividades que expressam as tensões do povo imigrante em fases distintas, como: a partida da Europa, a chegada no Brasil, a experiência no mundo rural e a mudança e transformação das regiões em ambientes urbanos. Representação que a literatura de Helena Kolody recria na história. Como coloca Pesavento: As imagens são criação humana dotada de propriedade semântica. Imagens são forma que se dá a ver e a ler, portando significados. ${ }^{38}$ Significados esses que levam Helena Kolody e sua poesia ao reconhecimento e representatividade dentro do Estado do Paraná, levando a cultura imigrante para diferentes leitores em diferentes perspectivas e visões.

\footnotetext{
${ }^{36}$ Os ucranianos chegaram ao Paraná entre 1895 e 1897. Mais de 20 mil Imigrantes chegaram ao Estado e formaram suas principais colônias em Prudentópolis e Mallet. Estão presentes também nos municípios de União da Vitória, Roncador e Pato Branco. Hoje o Paraná abriga a grande maioria de ucranianos que vivem no Brasil: 350 mil dos 400 mil imigrantes e descendentes. (Secretaria de Estado do Turismo - SETU - http://www.cidadao.pr.gov.br). Para maiores informações e dados sobre os imigrantes ucranianos no Paraná consultar: GUÉRIOS, Paulo R. A imigração ucraniana ao Paraná: memória, identidade e religião. 1. ed. Curitiba: Editora da UFPR, 2012. v. 1. 278p. ANDREAZZA, Maria Luiza. O Paraíso das Delícias: um estudo da imigração ucraniana -1895-1995. Curitiba. Aos Quatro Ventos, 1999; HORBATIUK, Paulo. Imigração Ucraniana no Paraná. $1^{\circ}$ Edição. Mallet: Uniporto, 1989.

${ }^{37}$ FONTES, op. cit., p. 35.

${ }^{38}$ PESAVENTO, Sandra Jatahy. História e literatura: uma velha-nova história. Nuevo Mundo Mundos Nuevos. Debates, 2006, p. 57.
} 
Kolody, ao representar a suas experiências nos poemas, se coloca como narradora e protagonista dos fatos que envolvem seus versos e histórias. A imagem da colona, da filha de imigrantes, da professora do interior, da mulher religiosa, torna-se, na interpretação de Fontes, uma parte integrante do mundo que representa o artista no movimento do campo que está inserido e de certa forma lhe é compreensível. Vejamos na citação da autora:

Refletir sobre uma vida vivida pode ajudar a compreender os estados e as motivações do sujeito que é obra e da obra de que é sujeito. Bourdieu reestabelece a importância do pensamento cientifico para a compreensão do fenômeno artístico. Não pretende, com isto, rebaixar o produtor de arte, mas analisa-lo a partir de sua movimentação nos diversos campos, considerando a maneira particular como ele se relaciona com as condições de exercício da literatura de sua época. Ou seja, como alguém que tem respostas muito próprias as solicitações sociais, tendo sempre em vista que sua enunciação e parte integrante do mundo o qual supostamente representa. ${ }^{39}$

As percepções de Kolody sobre os imigrantes e a sua consagração no meio literário, como a porta voz dos povos eslavos, se dá ao fato da autora reverenciar apenas o lado positivo dos mesmos. Como coloca Bourdieu: o poder propriamente simbólico de fazer com que se veja e se acredite, de trazer à luz experiências do mundo natural e do mundo social, e, por essa via, de fazê-las existir. ${ }^{40}$

Kolody fez existir o mundo dos imigrantes através de sua poesia. Apesar das formas específicas de se interpretar, os poemas possuem características, e sua definição está sujeita ao modo de construção que por sua vez se encontram em constante movimento, nos imaginários recriados pela poetisa. Helena tematiza um Paraná estereotipado na figura do imigrante ideal, os outros, os índios, os negros, os caboclos, estes sequer interagem com os imigrantes em seus poemas.

Para tanto, Kolody incorpora ingredientes que nos levam ao sentido regional de sua poesia, não somente por enfatizar o discurso dos imigrantes, ou retratar os símbolos do Paraná, mas pelo modo e associação com que a autora utiliza de diferentes elementos em sua composição poética. Problematizamos tal referência com as palavras de Durval Muniz de Albuquerque Júnior:

[...] a ideia de que o regional ou o local seria o lugar da experiência cotidiana e imediata dos homens, seria um lugar para ser pensado existencialmente, lugar com o qual os homens manteriam vínculos afetivos e emocionais, lugar de radicação das memórias e das tradições, lugar que serviria de mediador

\footnotetext{
${ }^{39}$ FONTES, op. cit., p. 40.

${ }^{40}$ BOURDIEU, Pierre. Coisas ditas. São Paulo: Brasiliense, 1990, p. 176.
} 
para o acesso e para a relação com recortes e identidades espaciais mais vastas, como: outras regiões, a nação e o estrangeiro, lugar, portanto, não ameaçador, não desconhecido, lugar familiar, a própria casa dos homens, portanto, nada mais normal que seja um lugar ligado a e definido pelas próprias operações cotidianas e rotineiras, as próprias operações que se passam no interior de uma casa ou de uma família: a região ou o local seria o lugar de nascimento ou da morte, o lugar de uma dada maneira de comer ou de beber, o lugar de uma dada forma de vestir, de falar, de cantar e de contar, de se divertir, de crer e de ser. ${ }^{41}$

Ao pensarmos as palavras de Durval e fazermos ligação com Kolody, percebemos que o Paraná é o lugar em que a autora estabelece suas raízes, seus vínculos tanto emocionais como artísticos. Helena não só se coloca como um recorte dentro do Estado, mas sim se estabelece como poeta paranaense, utiliza-se do simbolismo, da cultura e de seu cotidiano de ascendente de imigrante no Estado para estabelecer a sua arte. A autora exerce de fato uma relação de significados e realidades do seu cotidiano à sua poética. Como nos coloca Cruz: ${ }^{42}$ Helena Kolody - herdeira da uma tradição modernista e poeta da modernidade procura constantemente no quotidiano a matéria de sua lírica, a realidade entrelaçada à maneira de compor as relações entre poesia e vida. O enlace dessa relação entre a sua poesia e sua vida se dá por meio dos diferentes sentidos. A sua poesia se completa e adquire significado, estabelecendo vínculos culturais e afetivos com os lugares e pessoas. Sua poética constrói um sentido para a saga imigrante, para o cotidiano e para sua arte.

Segundo Bourdieu: ${ }^{43}$ O produtor do valor da obra de arte não éo artista, mas o campo de produção enquanto universo de crença que produz o valor da obra de arte como fetiche ao produzir a crença no poder criador do artista. Ou seja, inserida no campo Simbolista e influenciada pelo Paranismo, são os paranistas que irão consagrar Kolody e tornar sua poesia como chave de leitura sobre os imigrantes eslavos no Estado. Nesse sentido, a representação que a poetiza constrói em torno do cotidiano e do habitus do imigrante, se dá a partir da inserção do imigrante como agente transformador e civilizador do Estado.

De acordo com Bourdieu, por meio da linguagem se reforça, fixa e viabiliza os elementos de controle impostos pelas classes dominantes. Um dos elementos fortes de seu trabalho é mostrar como os intelectuais não atuam de forma neutra, mas dentro de parâmetros estabelecidos pelos grupos

\footnotetext{
${ }^{41}$ ALBUQUERQUE JÚNIOR, Durval M. O Objeto em Fuga: algumas reflexões em torno do conceito de região. Fronteiras (Campo Grande), v. 10/17, p. 55-67, 2008, p. 57.

${ }^{42}$ CRUZ, op. cit., p. 269.

${ }^{43}$ BOURDIEU, Pierre. Campo do Poder, Campo Intelectual e Habitus de Classe. In: Economia das Trocas Simbólicas. 3ª ed. São Paulo: Perspectiva. 1992, p. 192.
} 
dominantes na sociedade. O contexto para referirmos a Kolody e seu campo de produção cultural, está ligado não só a vida da autora e sua ascendência eslava, mas ao modo com que a autora busca levar os símbolos do Estado e a afirmação do povo imigrante, segundo preceitos oficiais que os tomam como sujeitos-chave para colonizar o Paraná. Apesar de um campo heterogêneo, Kolody difunde a "voz do imigrante" como sendo única em seu discurso.

Nesse sentido, a consagração intelectual de Kolody remete-se a um ambiente simbólico, pautado por intervenções e influencias literárias e culturais. Os imigrantes eslavos, os símbolos paranaenses, a natureza do Estado, são elementos presentes na narrativa kolodyana que marcam o reconhecimento cultural de seus poemas. Kolody usa de fatos e experiências que eram sua bagagem cultural e existencial. o que segundo Pierre Bourdieu, podemos analisar como:

A cultura, que é produto desta divisão mágica tem valor de sagrado. E, de fato, a consagração cultural submete os objetos, pessoas e situações que ela toca a uma espécie de promoção ontológica que se assemelha a uma transubstanciação. ${ }^{44}$

Nesse processo, alguns objetos são "tocados" e passam por essa transformação de status. Como A araucária em que Helena coloca como "forte e altiva", assim seria o Estado e seu povo, um reflexo de status da população integrante. Transformando-se, assim, em produto cultural a ser consumido não apenas pela cultura popular, mas por pessoas "distintas", artistas e críticos em busca de uma definição cultural à consagração intelectual. Portanto, não se trata apenas de pensar na qualidade de uma obra artística, mas também nas diferentes condições em que essa obra é recebida por um determinado público.

\section{A influência do Paranismo: o imigrante ideal}

Helena Kolody é consagrada por muitos críticos literários paranaenses como vimos no texto acima. Seu reconhecimento enquanto intérprete da cultura paranaense se deve pelo fato de Helena representar em muitos de seus poemas a cultura imigrante eslava, mais especificamente os ucranianos, na qual a autora é ascendente. $O$ discurso da poetisa sobre os imigrantes revela-se durante toda sua obra, não há um livro especifico com poemas dedicados meramente ao povo ucraniano, mas sim diversos poemas em praticamente todos os seus escritos. Mas como a consagração intelectual e cultural de Helena

\footnotetext{
${ }^{44}$ BOURDIEU, Pierre. A distinção: crítica social do julgamento. São Paulo: Edusp; Porto Alegre, RS: Zouk, 2007, p.14. Disponível em: https://edisciplinas.usp.br/pluginfile.php/312144/mod_resource/content/1/ Bourdieu\%20-\%20A\%20Distin\%C3\%A7\%C3\%A3o.pdf
} 
Kolody representa os imigrantes em sua obra? o que os símbolos e a sua ligação com o paranismo refletem na representação da identidade imigrante?

O que Helena constrói sobre os imigrantes é a visão do povo que migrou de um país em guerra e com diversos conflitos contra invasores. O Brasil foi um dos destinos para os imigrantes e o Paraná a terra que traria prosperidade para esse povo. o clima, o tipo de solo, seria o ideal para receber os povos eslavos. o que percebemos no discurso poético kolodyano, é uma visão positiva dos imigrantes, o apego com a cultura da pátria de seus pais. A representação dos imigrantes está ligada a identidade que os artífices do Estado almejavam. Vemos, então, que os poemas de Kolody apresentam o idealismo do povo perfeito para o Paraná, como os paranistas usam em seus discursos. A crítica positiva de sua obra se dá muito pela fala de outros artistas também descendentes de imigrantes, que também promoveram o esquecimento de outros caminhos e culturas presentes na formação populacional do Estado. Como visto anteriormente, o poema "Araucária", remete o discurso paranista de Helena, o símbolo do Paraná. Marco Aurélio de Souza faz uma reflexão de Kolody com o Paranismo e o poema Araucária: Eleito pelos paranistas como símbolo máximo do Estado, a imagem poética da araucária criada por Helena faz eco aos elogios e exaltações do pinheiro por parte dos escritores e artistas plásticos ligados ao movimento. ${ }^{45}$

Os pinheirais aparecem ao decorrer de sua obra evidenciando mais a força simbólica do movimento em suas poesias. A exaltação ao Estado, aos seus símbolos e ao povo imigrante é contínua em sua obra, e que remetem para a influência Paranista. Vejamos novamente o que coloca Souza:

Em suas primeiras obras, os pinheiros e pinheirais ainda vão aparecer em
inúmeros poemas, não mais como personagem que rouba a cena, mas compondo
a paisagem com sua força simbólica. Helena dava um passo para a literatura
moderna, alocando os pinheiros na paisagem e deixando gradualmente em
suspenso (mas não abandonando por completo) a exaltação romântica, lírica
e simbolista da árvore-símbolo - impulso tipicamente paranista. ${ }^{46}$

Vejamos como exemplo outro poema, intitulado "Dor" em que a autora coloca o pinheiro como protagonista de sua escrita. Percebemos o valor simbólico e o discurso referente ao Estado e sua paisagem, como o nome da obra Paisagem interior de 1951. Segue o poema:

\footnotetext{
${ }^{45}$ SOUZA, M. A. Paisagens do interior: regiões de memória e outros lirismos na primeira poética de Helena Kolody (1941-1951). Uniletras, v. 35, p. 287-300, 2013, p. 290.
}

${ }^{46}$ Ibidem, p. 291. 
Tua dor é como um incêndio de inverno

Na floresta:

O fogo tisna o tronco dos carvalhos,

Consome as frondes dos pinheiros,

Crepita nas ervas mesquinhas

E morre.

Uma procissão de troncos mutilados

Queda da campina.

Tens, por isso, a lembrança povoada de espectros.

Ateaste o fogo do sofrimento

Em minha alma impetuosa:

As chamas subiram até o céu

E lamberam as nuvens

Com línguas gigantescas;

A floresta se estorceu

Gemeu e estalou

No paroxismo;

Os pinheiros arderam como tochas

Até o fim.

Só ficou uma lápide de cinzas,

Porque a minha dor é a destruição total. ${ }^{47}$

A destruição dos pinheiros e a dor da poeta marcam a sua ligação e conexão com o símbolo do Estado. Helena, ao referir-se ao pinheiro e colocar ele em sua poética, cria um vínculo estético, que dá sentindo a sua subjetividade simbólica com o Paraná. A dor de Helena, não é só pela paisagem destruída, mas a dor de quem se considera parte da paisagem paranaense. No mesmo poema Helena cita os carvalhos, árvores consideradas típicas das florestas da Europa. Se a destruição dos pinheiros reflete o sentimento de dor pelo Paraná, a destruição dos carvalhos refere-se ao sentimento da pátria de seus pais, a Ucrânia.

Determinados símbolos representam a dor do eu lírico de Kolody. Segundo Souza: com a junção poética de duas espécies extremamente simbólicas - a araucária e o carvalho - em uma mesma paisagem, Helena Kolody exprime a dor através de uma queimada na qual os símbolos de sua terra ancestral e de sua terra natal são dizimados pelo fogo. ${ }^{48}$

${ }^{47}$ KOLODY, Helena. Dor. In: Viagem no espelho. Curitiba: Editora da UFPR. 5a. Ed., 2001, p. 231-232. ${ }^{48}$ SOUZA, op. cit., p. 291. 
O imaginário criado por Kolody marca seu estado de arte. Para isso, ela utiliza-se da simbologia da natureza, da arquitetura, do povo imigrante e do cotidiano. Marca as regiões de memória presentes em sua poética, estabelecendo relações entre os elementos da paisagem do interior, da cidade e os significados atribuídos culturalmente aos imigrantes nos poemas da autora. Através de sua produção poética seu sentimento torna-se uma ligação entre os imigrantes e o que ela vê da cultura nas regiões em que vive. Entre símbolos do Estado oficial e da cultura eslava, a poética kolodyana não se desprende em muitos momentos do sentimento e da visão do eu- lírico. Cada região que a poetiza vive, é um local heterogêneo, porém as suas representações poéticas nos levam a pensar em um Paraná eslavo. A forma de vida, a influência eslava de sua família e seu percurso são incorporadas a sua produção cultural. Vejamos a citação de Luiza Cristina dos Santos Fontes:

Os textos de Helena Kolody, voluntariamente ou não, exploram representações e simbologias que vão sendo paulatinamente incorporadas pelo imaginário popular: o Paraná como estado de progresso e civilidade; a imagem do semeador; a abundância da natureza representada, em outros, pelo pinheiro do Paraná além de simbolizar a altivez do cidadão paranaense, foi indiscriminadamente utilizado na confecção de casas de madeira, hoje, emblematicamente, referenciadas etnias mais numerosas migradas para o estado, em fins do século XIX e primeiras décadas do século XX: a polonesa, a eslava, a germânica, a italiana. ${ }^{49}$

De certa maneira, a relação de identidade cultural está relacionado aos escritos de Helena. Segundo Oliveira, ${ }^{50}$ as identidades culturais nunca se apresentam de forma única, constituindo-se sim em reapresentações, teatro, simulacro, híbridas por excelência. Helena Kolody transfere a ideia de identidade do imigrante em seus poemas, a identidade do imigrante ideal construída pelo Movimento Paranista. Porém, o que percebemos é que o imigrante ideal é a representação do que o movimento desejava. Segundo Pereira:

Através da arte, portanto, esses homens tentarão construir esta identidade cultural do Paraná, onde até mesmo um tipo ideal será forjado apesar de toda a heterogeneidade da região, que através da mistura de raças dificultava tal construção. Era preciso transformar todos em paranistas, em homens de amor pelo Paraná, que lutassem pela construção dessa nova terra de ideais nobres e elevados; pela sociedade do trabalho. ${ }^{51}$

\footnotetext{
${ }^{49}$ FONTES, op. cit., p. 61.

${ }^{50}$ OLIVEIRA, E. D. Migração, Identidade Cultural e História Oral: percurso possível de pesquisa. Monções - v. 2, p. 170-181, 2015.

${ }^{51}$ PEREIRA, op. cit., p. 161.
} 
Kolody, em seu projeto criador, reafirma a visão do imigrante que o movimento idolatrava. Contando ainda que o campo cultural em que a poeta se insere, passa pela construção de um Estado ainda em afirmação seja no âmbito político ou cultural. Podemos relacionar Helena Kolody e os imigrantes ucranianos, tendo as características do que era ser paranaense, pelo discurso de Romário Martins em 1927, encontrado na tese do historiador Geraldo Leão Veiga de Camargo:

Paranista é todo aquele que tem pelo Paraná uma afeição sincera, e que notavelmente a demonstra em qualquer manifestação de atividade digna, útil à coletividade paranaense. Esta é a acepção em que o neologismo, si é que é neologismo, é tido nesse nobre movimento de idéias e iniciativas contidas no Programa Geral do Centro Paranista (...) Paranista é aquele que em terras do Paraná lavrou um campo, cadeou uma floresta, lançou uma ponte, construiu uma máquina, dirigiu uma fábrica, compôs uma estrofe, pintou um quadro, esculpiu uma estátua, redigiu uma lei liberal, praticou a bondade, iluminou um cérebro, evitou uma injustiça, educou um sentimento, reformou um perverso, escreveu um livro, plantou uma árvore. ${ }^{52}$

Se o paranaense era todo aquele quem tinha a feição e fez alguma coisa de destaque no estado, Kolody fez isso duplamente. Seus poemas caracterizam este estereótipo paranista, os símbolos do Estado, o povo imigrante, evidenciando a sua contribuição intelectual com o Paraná. Além disso, como filha de imigrantes ucranianos, a poeta escreve sobre os eslavos como se tivesse participado de todo processo imigratório como protagonista. Desta forma, percebemos que os poemas kolodyanos como produto cultural que ganham destaque como criação artística na medida em que preserva a visão do estado e do seu contato com a sociedade que o consome. Observamos que o Paraná de Kolody é o Paraná dos imigrantes e seus descendentes. A incorporação europeia que a autora não se desprende ao longo de suas obras, recorrendo à história dos ancestrais, desde sua constituição enquanto povo, valoriza os fatos, e a saga dos imigrantes, tentando transformá-los num acontecimento marcante em seus livros.

Percebemos, também, através dos poemas com a temática sobre os imigrantes, uma visão singular da autora. Helena revela nos seus textos, um imigrante que torna-se parte do cotidiano do Paraná. Ela inclui a temática do imigrante eslavo, em um Brasil considerado "diferente", seja pelos povos

\footnotetext{
${ }^{52}$ CAMARGO, Geraldo Leão Veiga de. Paranismo: arte, ideologia e relações sociais no Paraná. 1853 - 1953. 2007. Tese - Curso de História, Universidade Federal do Paraná, Curitiba, 2007, p. 157.
} 
imigrantes, seja pelo clima e até mesmo pelo aspecto físico da população. Vejamos nas palavras de Wilson Martins uma colocação sobre essa analogia:

"A voz das raízes" ecoa em outro poema, como também em "Imigrantes eslavos", quadro chagalliano em que a poesia recupera a paisagem humana do "Brasil diferente" "Cabeça branca de neto/cabeça branca do avô/Luar noturno e geada/Que é orvalho de madrugada. [...] Sonham um sonho impreciso/A estepe, a troika de guisos/ a neve, a dança ligeira..." ${ }^{53}$

O que Martins coloca é o que o Movimento Paranista sempre pregou a formação de uma identidade diferente do restante do Brasil. Se pensarmos a figura do negro na formação do Estado e mesmo nas representatividades artísticas, como na poética kolodyana, é praticamente nula. Segundo Camargo:54 No Paraná, como já vimos, apesar da influência demográfica e na economia, a presença do negro, seja na visão "oficiosa" da constituição da população por Romário Martins, seja nas representações artísticas, são praticamente inexistentes. Schneider problematiza esta questão apontando para os estereótipos perpetuados na historiografia:

\begin{abstract}
Aliás, esta é a tônica de grande parte da construção histórica até hoje em elaboração ou reelaboração, o que corrobora com a perpetuação de estereótipos que fazem do Paraná o lugar do imigrante, do laborioso, do morigerado, do pioneiro vencedor. Os outros, os caboclos, os posseiros, os afrodescendentes, os índios e os mestiços, foram ignorados ou sua participação aparece como de menor importância. Escrevendo em um tempo em que se buscava construir uma história harmônica - eurocêntrica, pautada no sentido de progresso e da industrialização - forjava-se um tipo ideal, no caso um imigrante ideal, heroicizado por esta historiografia. Resultado desta construção imagética foi a solidificação de imagens e de idéias que fazem compreender visões estereotipadas da história, visões que consolidam acriticamente regiões de sentidos que passam a ser encenados e representados nas comemorações oficiais de muitos municípios que se auto proclamam "germânicos", "ucranianos", "italianos" etc. 55
\end{abstract}

Nos poemas de Helena Kolody é preciso perceber o caminho social e cultural, seja na representação de suas raízes ou na descrição do cotidiano dos

\footnotetext{
${ }^{53}$ VENTURELLI, Paulo (Org.). Helena Kolody: poesia feito gente. In: Helena Kolody. Curitiba: Ed. da UFPR, 1995 , p. 52

${ }^{54}$ CAMARGO, op. cit., p. 51.

${ }^{55}$ SCHNEIDER, Claércio Ivan. Histórias e historiografias do Paraná: estereótipos, revisionismos e problemáticas para o ensino de história. In: Anais do II Congresso Internacional de História UEPG-UNICENTRO. 2015, Ponta Grossa, p. 06. Disponível em: http://www.cih2015.eventos.dype.com.br/resources/anais/4/1430409644_ ARQUIVO_ARTIGO-HistoriasehistoriografiasdoParana-estereotipos,revisionismoseproblematicasparaoe nsinodeHistoria.pdf
} 
imigrantes ucranianos no Paraná. A ligação discursiva dos imigrantes com as influências do Movimento Paranista se dá pela busca de uma identidade oficial ao Estado, pautado na afirmação dos povos europeus em um território que para muitos era semelhante ao da Europa, dado esse pelo clima e pelo tipo de terra. Vejamos nas palavras de Geraldo Leão Veiga de Camargo em um estudo sobre os imigrantes como a etnia idealizada para o Paraná:

o clima foi muito utilizado para justificar o caráter pretensamente superior do paranaense, porque muito ameno e semelhante aos climas europeus, em contraste com a canícula tropical que impediria o desenvolvimento de uma civilização à europeia. ${ }^{56}$

O clima ameno do estado paranaense foi também tratado por Helena Kolody, ao se referir aos imigrantes e ao Estado. A poeta utiliza-se da experiência do clima e das estações de inverno e outono, para retratar em seus textos, aspectos da cultura imigrante, a adaptação com o território do Paraná, evidenciando a natureza e novamente o símbolo do pinheiro. Na poesia "Paisagem de outono", original da obra A Sombra do Rio, de 1951, Kolody, enaltece a estação com a figura do pinheiro. Vejamos a poesia:

\author{
Baixinho, o vento assobia \\ Na grimpa dos pinheirais \\ Alto céu, claro céu \\ A transbordar de sol. \\ Vestem-se esguias pereiras \\ De amarelo e vermelhão \\ Uma cigarra vadia \\ Celebra a glória do dia \\ Em suas asas musicais. \\ Farfalham folhas nas frondes, \\ Sussurram folhas, ciciam. \\ Claro céu, alto céu, \\ A refletir-se \\ No inquieto espelho das águas. \\ As folhas mortas deslizam, \\ Por entre nuvens, no azul. \\ Flutuam sonhos frustrados \\ Nas águas do pensamento.
}

${ }^{56}$ CAMARGO, op. cit., p. 26. 
Borboletas agonizam

A sombra dos roseirais.

Farfalham folhas nas frondes,

Sussurram folhas, ciciam.

Verdes reflexos,

Nuanças azuis...

Glória festiva de luz.

Trágica e luminosa

Beleza do outono. ${ }^{57}$

Kolody promove a junção de elementos da natureza indo ao encontro dos símbolos construídos pelo Movimento Paranista. Conduz-nos a pensarmos a exuberância da natureza, o clima e o culto à terra. Representação que nos leva a pensarmos também o povo imigrante e sua ligação com o cultivo da terra nas regiões do interior que a poeta percorreu, exaltando as belezas naturais do Estado, identificando um clima diferente das demais regiões do país. A própria palavra grimpa, utilizada pela autora, mostra uma diferenciação ao referir-se ao sapé. Esta posição de defesa e exaltação do imigrante, no caso, do imigrante eslavo, vai ao encontro de muitos preceitos oficiais, incumbidos na tarefa de edificar uma história harmônica, centrada na adaptação, na religiosidade e no trabalho dos imigrantes como elementos cruciais para o Paraná grandioso que se construía. A consagração de Helena no campo intelectual é resultado da defesa e promoção destas posições.

Otavio Paz coloca que o homem é um ser que se criou ao criar a linguagem. Pela palavra, o homem é uma metáfora de si mesmo. Nesse sentido, a essência da linguagem kolodyana é simbólica porque consiste em representar um elemento da realidade por outro. A poetisa faz usos de uma linguagem que reflete tanto o cotidiano quanto a fala dos imigrantes eslavos no Paraná, promovendo, por meio da poesia, um conjunto de símbolos, de representações e de memórias que os tornam personagens centrais do Estado. 0 poema constrói o povo porque o poeta reproduz a linguagem e vai à fonte original. Vemos nos poemas de Kolody, que a sociedade se depara com os fundamentos de seu ser, com sua palavra primeira, frente aos fatos que ocorreram.

Por tudo isso, destacamos que persiste nas poesias de Helena Kolody um conjunto de práticas que afirmam uma singularidade material e simbólica aos imigrantes ucranianos. Tornam-se assim um ritual de exaltação aos elementos e símbolos do Paraná, bem como da cultura imigrante eslava e,

${ }^{57}$ KOLODY, op. cit., 2001, p. 175-76. 
ao mesmo tempo, transformam-se em uma experiência social coletiva. Para Octavio Paz, a linguagem do poeta é a mesma linguagem de sua comunidade, qualquer que esta seja..$^{58}$

\section{Considerações Finais}

No projeto criador de Helena Kolody evidencia-se detalhes da cultura dos imigrantes ucranianos por meio de suas memórias e experiências de vida. A conjuntura social e intelectual da qual Kolody fez parte influenciou, de forma direta e indireta, na sua escrita poética, perceptível tanto na escolha e na abordagem dos seus temas quanto na crítica literária que consagra a poetiza como intérprete "autorizada" do Paraná dos imigrantes. A problematização que fizemos buscou mostrar o campo de produção cultural na qual a autora estava submetida, bem como o campo intelectual onde consegue o reconhecimento e a consagração. Nesse sentido, articulamos situações referentes a vida da poetisa, sua ascendência ucraniana, que nos serviram para uma abordagem direta de como sua poesia representa a imigração ucraniana no Estado, com as influências do campo literário e histórico - em especial ao Movimento Simbolista e Movimento Paranista - do qual faz referência e uso da simbologia oficial.

No que se refere a consagração de Kolody no campo literário e historiográfico paranaense, analisamos diferentes falas e autores que identificam o projeto criador de Helena segundo o seu campo de produção cultural. Ou seja, identificamos tanto na fortuna crítica, como em autores contemporâneos estudos que evidenciam a ligação ou influência de Kolody com as instituições promotoras de uma identidade oficializada aos paranaenses. Chamou atenção, em especial, a influência dos ideais do Movimento Paranista, em particular aqueles ligados a caracterização do imigrante ideal, realçando os valores, sentidos e símbolos que identificam os imigrantes ou os transformam em paranaenses.

Como visto, a sua poética nos envolve em constatações para o entendimento de diferentes dimensões de uma história sensível, emotiva, construída poeticamente para representar a saga e a condição de vida dos imigrantes ucranianos no Paraná. Buscamos mostrar as potencialidades que a arte poética de Kolody sintetiza para os estudos históricos, abrindo caminhos interpretativos para o entendimento crítico da construção identitária dos imigrantes a partir das influencias do Movimento Paranista. As marcas culturais presentes

${ }^{58}$ PAZ, Octavio. Os filhos do barro: do romantismo à vanguarda. Rio de Janeiro: Nova Fronteira, 1984, p. 10. 
ao longo da sua obra são registros que nos levam a identificar elementos diversos para se retratar a identidade ucraniana no Estado como: o idioma, a religiosidade, os símbolos, o trabalho e, principalmente, o habitus morigerado do estilo de vida dos imigrantes.

Por outro lado, percebemos que as representações da cultura e da identidade ucraniana nos poemas de Kolody estabelecem elos entre as experiências de vida da autora e suas memórias. Ou seja, o que é representado em sua poética vai ao encontro com o sentido de pertencimento de Helena, a ponto de ser considerada a porta-voz dos imigrantes ucranianos no Estado. Kolody imprime marcas, sentidos, definições em prol de um grupo étnico que representa e que é representado também pelos órgãos oficiais, na medida em que são tomados como modelo de colonização, por sua moral, sua índole e valores civilizatórios. Esse é o Brasil diferente de Wilson Martins mas também de Helena Kolody, diferente porque escamoteia as diferenças étnicas que transformariam o Paraná num Brasil comum.

Artigo recebido para publicação em 27/05/2018 Artigo aprovado para publicação em 30/08/2018 